\title{
Co-localisation of cocaine- and amphetamine- -regulated transcript peptide and vasoactive intestinal polypeptide in the myenteric plexus of the porcine transverse colon
}

\author{
K. Palus, L. Rytel \\ Department of Clinical Physiology, Faculty of Veterinary Medicine, University of Warmia and Mazury, Olsztyn, Poland
}

[Received 18 April 2013; Accepted 24 May 2013]

\begin{abstract}
Cocaine- and amphetamine-regulated transcript peptide (CART) is a substance, which can play the role of neuromediator and/or neuromodulator in nerve structures within the gastrointestinal tract. However knowledge concerning its functions and co-localisation with other neuronal factors is rather scarce.

During the present investigation the co-localisation of CART and vasoactive intestinal polypeptide (VIP) in the neurons of meyenteric plexus within the porcine transverse colon was studied using double immunofluorescence technique and semiquantitative arbitrary scale of the frequency of presence CART+/VIP+, CART + NIP- and CART-IVIP+ neuronal cells. The most often $(+++)$ CART-IVIP+ neurons were encountered, neurons simultaneously immunoreactive to CART and VIP were observed somewhat rarer (++) and only single (+) CART+/VIP- perikarya were visible. The present study reports for the first time on the co-localisation of CART and VIP in myenteric neurons of the porcine transverse colon. (Folia Morphol 2013; 72, 4: 328-332)
\end{abstract}

Key words: cocaine- and amphetamine-regulated transcript (CART), vasoactive intestinal polypeptide (VIP), transverse colon, immunofluorescence, pig

\section{INTRODUCTION}

It is well known that the gastrointestinal (GI) tract is controlled both by the enteric nervous system (ENS) located in the wall of stomach and intestines $[12,15]$ as well as by extrinsic autonomic innervation $[21,23,29]$.

The ENS in the large intestine of humans and big mammals (such as pig) is organised into 3 intramural ganglionated plexuses: the myenteric plexus (MP) - located between the longitudinal and circular muscle layers, the outer submucous plexus - near the circular muscle layer and the inner submucous plexus - between the muscularis mucosa and lami- na propria. These plexuses comprise wide range of neurons which can have various functions, contain different neurotransmitters and/or neuromodulators and can change their chemical coding under various pathological factors [8-11].

One of neuronal factors, which has been observed in enteric neurons, is cocaine- and amphetamine-regulated transcript peptide (CART). This peptide was discovered in 1981 in ovine hypothalamus [24] and till now it has been described in various parts of the ENS in numerous mammals, including humans [27].

In spite of this fact, the exact functions of CART in the GI tract have not yet been completely explained.

Address for correspondence: K. Palus, Department of Clinical Physiology, Faculty of Veterinary Medicine, University of Warmia and Mazury, ul. Oczapowskiego 13, 10-718 Olsztyn, Poland, tel: +48 8952344 61, fax: +48 8952338 77, e-mail: katarzyna.palus@uwm.edu.pl 
Localisation of CART-like immunoreactive nervous structures - mainly in the MP and circular muscle layers suggests that this peptide is involved in the regulation of intestinal motility. Previous studies also show that CART can take part in the inhibition of feeding [20], reduction of gastric acid secretion [22], exacerbation of colonic motility [25], but mentioned above functions are likely realised via regulatory circuits located within the central nervous system. It has been confirmed by investigations on the motor activity of isolated wall fragments of stomach, small and large intestine, where the contractile or relaxatory activity of CART was not been observed [6].

Previous investigations also described changes in the number of CART-positive nervous structures in the ENS under various pathological factors [14], what may suggest neuroprotective functions of CART in the digestive system.

The one of investigatory methods on putative CART functions within the Gl tract is study concerning the co-localisation of this peptide with other, better known, neuronal factors. During present investigation the co-localisation of CART and vasoactive intestinal polypeptide (VIP), which is known as a potential mediator of smooth muscle relaxation, the stimulator of intestinal fluid secretion and the regulator of blood flow in the Gl tract [1] has been studied within the MP of the porcine transverse colon.

\section{MATERIALS AND METHODS}

The present study was performed on 5 immature female pigs of the Large White Polish breed (approximately 8 weeks old), which were kept in standard laboratory conditions with admission to species-specific feed and water ad libitum. All experimental procedures were carried out in compliance with the instructions of the Local Ethical Committee in Olsztyn (Poland), with special attention paid to minimising any stress reaction during and after the surgery.

The animals were euthanised by an overdose of sodium thiopental (Thiopental, Sandoz, Kundl-Rakúsko, Austria; given intravenously) and then perfused transcardially with $4 \%$ buffered paraformaldehyde ( $\mathrm{pH}$ 7.4) prepared ex tempore. The same fragments (ca. $1 \mathrm{~cm}$ long) of the cranial transverse colon located near the border between the ascending and transverse colon were collected. Then they were post-fixed by immersion in the same fixative, rinsed in $0.1 \mathrm{M}$ phosphate buffer $\left(\mathrm{pH} 7.4,4^{\circ} \mathrm{C}\right)$ for several hours and, finally, stored in $18 \%$ buffered sucrose at least 7 days. Next samples were sectioned into $10 \mu$ m-thick cryostat sections, which were then subjected to routine double-labelling immunofluorescence as described previously by Gonkowski et al. [15], using combinations of antisera raised in different species and directed towards CART (mouse monoclonal; R\&D System, Minneapolis, MN, USA, cat. no. MAB 163; working dilution 1:1000) and VIP (rabbit polyclonal; Biomol, Hamburg, Germany, cat. no. VA1285; working dilution 1:6000). Primary antisera were visualised by species-specific secondary antisera conjugated to FITC or biotin (all from Jackson Immunochemicals, USA, in a working dilution of 1:800). The latter antibodies were then visualised by a streptavidin-CY3 complex (Jackson, 1:8000). Standard controls, i.e. pre-absorption of the neuropeptide antisera with appropriate antigen, omission and replacement of primary antisera by non-immune sera were performed to test the antibodies and specificity of the method. The pre-absorption test was performed as follows: sections were incubated with "working" dilutions of primary antibodies directed toward CART and VIP, which had been preabsorbed for $18 \mathrm{~h}$ at $37^{\circ} \mathrm{C}$ with $20 \mu \mathrm{g}$ of appropriate protein CART (003-63, Phoenix Pharmaceuticals) or VIP (064-24, Phoenix Pharmaceuticals). These procedures completely eliminated specific stainings.

Myenteric plexus in 6 sections per animal were estimated. Labelled perikarya (only neurons with clearly-visible nucleus were included) were evaluated under an Olympus BX51 microscope equipped with epi-fluorescence and appropriate filter sets. To prevent double observations, the sections were located at least $100 \mu \mathrm{m}$ apart from each other.

Three various populations of myenteric neurons were studied: CART+/VIP+, CART+/VIP- and CART-NIP+. For the semiquantitative evaluation of the frequency of particular populations of neuronal cells an arbitrary scale was used, where $(-)$ means the absence of neurons, $(+)-$ single neurons, $(++)$ - rare cell bodies, $(+++)-$ depicts a common occurrence of perikarya.

\section{RESULTS}

The majority of myenteric ganglia of the porcine transverse colon observed during present investigation was devoid of neurons immunoreactive to CART and/or VIP but the dense of meshwork CART- and/or VIP-positive intraganglionic nerve fibres were present within them (Fig. 1A). In other ganglia all neuronal 

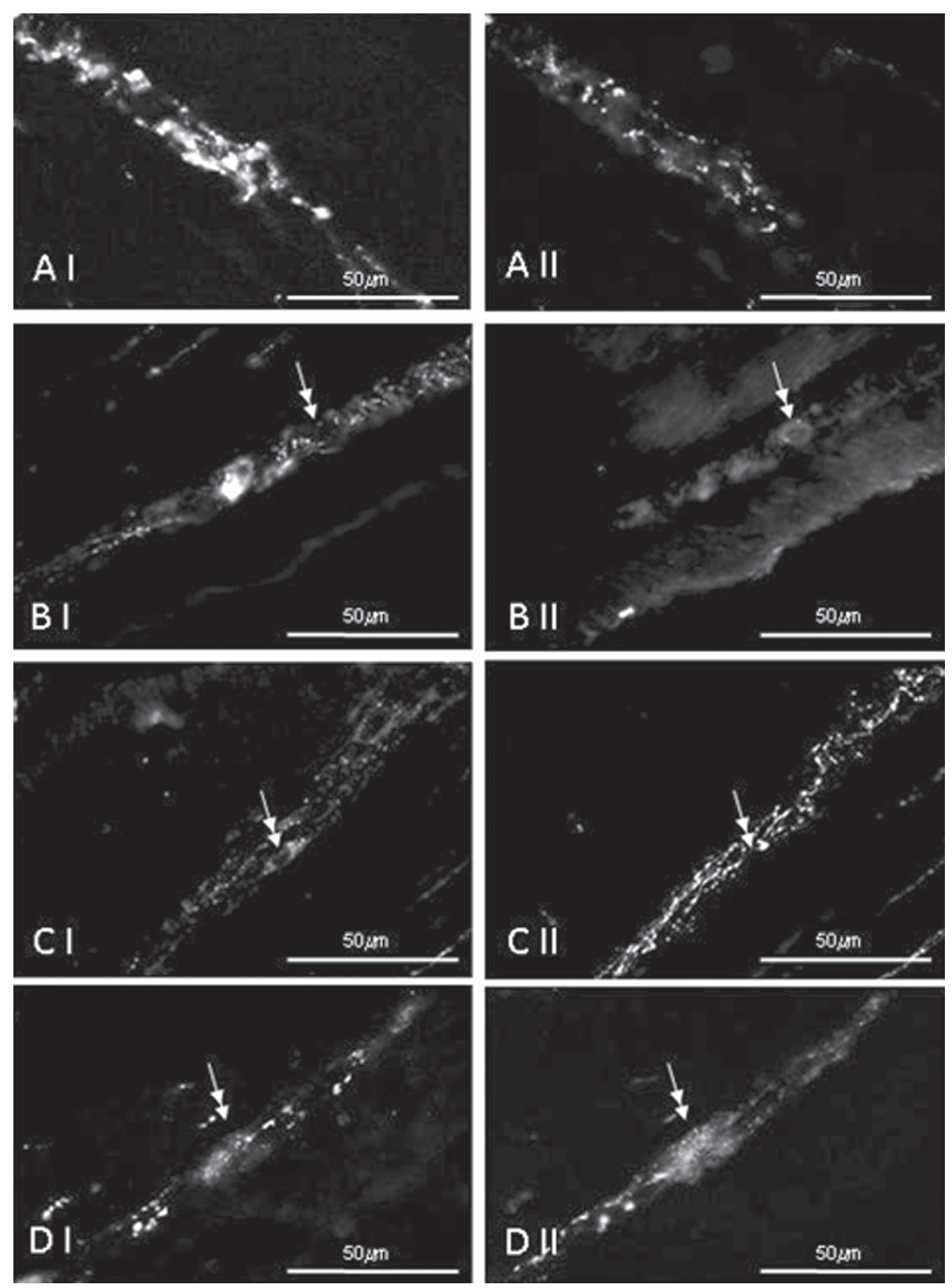

Figure 1. Co-localisation of cocaine- and amphetamine-regulated transcript (CART) (I) and VIP (II) in the myenteric plexus of the porcine transverse colon; A. Plexus with a dense meshwork of CART- and VIP-positive nerves; B. Neurons CART-NIP+ (double arrow); C. Neuron CART+NIP-(double arrow); D. Neuron CART+NIP+ (double arrow).

populations studied were observed. The most often $(+++)$ CART - VIP+ neurons were encountered. In the view of individual ganglia 1 or 2 such cell bodies were visible (Fig. 1B). Neurons co-localising CART and VIP were observed somewhat rarer $(++)$ and most often one such cell was visible in the view of particular plexus (Fig. 1D). CART+/VIP- perikarya were observed the least often. Only single such cells $(+)$ in the small number of MP was noted (Fig. 1C). In the present study visible differences in the frequency of appearance of CART and VIP co-localisation between particular animals were not observed.

\section{DISCUSSION}

In the present investigation, CART-like immunoreactive neurons was observed in the MP of the porcine transverse colon, what is in accordance with previous studies, where expression of CART was noted in different parts of the $\mathrm{Gl}$ tract in various species [13, 28]. The presence of CART in the nerve structures 
within the MP suggest that this peptide is involved in the intestinal motility regulatory processes. Notwithstanding, the exact functions of CART in the ENS remain unexplained. On the one hand CART has been previously described as an inhibitor of gastric acid secretion [22], a reducer of colonic motility [25] and inhibitor of nitric oxide - mediated relaxation in the colon, but on the other hand the studies on the motor activity of stomach and small intestine did not show any contractile or relaxatory actions of this peptide [6]. Moreover, some previous studies, which described changes in the number of CART-positive nervous structures in the ENS under various pathological processes of $\mathrm{Gl}$ tract in humans and pigs [17], can suggest neuroprotective functions of CART in the digestive system.

During the present study, the co-localisation of CART and VIP was observed in the MP both in cell bodies and intraganglionic nerve fibres. Obtained data show that not all VIP-positive neurons are immunoreactive to CART, but the vast majority of CART + cell bodies were simultaneously VIP-like immunoreactive. These results, together with previous studies, where CART+/NIP+ nerve structures were describe in the GI tract [26], may suggest that functions of CART and VIP can be similar, especially that it is well known that substances which co-localise in 1 neuron of the ENS often play similar roles [7].

VIP is above all known as an inhibitory neurotransmitter and/or neuromodulator, which causes the muscle hyperpolarsation and relaxation [19]. Moreover, VIP takes part in the blood flow regulation [18] and alters secretory actions of the Gl tract. Namely, this peptide increases the production of intestinal juice and bile, but suppresses the production of hydrochloric acid in the stomach [5]. VIP also is involved in the regulation of immunological processes [3] and is known as one of the important neuroprotective factor within the ENS. Previous studies have shown that this peptide can enhance the survival of neurons after axotomy and during lipopolysaccharide cell death [2] and this action of VIP is based on the influence of this peptide on glial cells cytokine production [4].

The co-localisation of CART and VIP, observed during the present investigation can suggest that at least some of mentioned above functions of VIP can be also realised by CART within the porcine transverse colon. Especially, CART can be involved in the promoting the survival of the porcine enteric neurons and in protection of these neuronal cells in intestinal disorders, neuronal stress or injury. This supposition is strongly supported by previous studies, where pathological factors increased CART-like immunoreactivity in the intestinal nervous structures [16] as well as by data showing that CART is able to promote the survival of rodent enteric neurons in vitro.

\section{CONCLUSIONS}

To sum up, the obtained results show that CART is present and co-localises with VIP in neuronal cells within MP of porcine transverse colon, what suggest coherent functions of both substances. However CART still remains an obscure neuropeptide and further investigations are necessary to explanation in detail its functions within the Gl tract in physiology and during pathological processes.

\section{REFERENCES}

1. Andersson PO (1984) Vascular control in the colon and rectum. Scan J Gastroenterol Suppl, 93: 67-78.

2. Arciszewski MB, Sand E, Ekblad E (2008) Vasoactive intestinal peptide rescues cultured rat myenteric neurons from lipopolysaccharide induced cell death. Regul Pept, 146: 218-223.

3. Bellinger DL, Lorton D, Brouxhon S, Felten S, Felten DL (1996) The significance of vasoactive intestinal polypeptide (VIP) in immunomodulation. Adv Neuroimmunol, 6: 5-27.

4. Brenneman DE, Philips TM, Hauser J, Hill JM, Spong CY, Gozes I (2003) Complex array of cytokines released by vasoactive intestinal peptide. Neuropeptides, 37: 111-119.

5. Burleigh DE, Banks MR (2007) Stimulation of intestinal secretion by vasoactive intestinal peptide and cholera toxin. Auton Neurosci Bas Clin, 133: 64-75.

6. Ekblad E, Kuhar MJ, Wierup N, Sundler F (2003) Cocaineand amphetamine-regulated transcript distribution and function in rat gastrointestinal tract. Neurogastroenterol Motil, 15: 545-557.

7. Furness JB (2000) Types of neurons in the enteric nervous system. J Auton Nerv Syst, 81: 87-96.

8. Gonkowski S, Calka J (2010) Changes in the somatostatin (SOM)-like immunoreactivity within nervous structures of the porcine descending colon under various pathological factors. Exp Mol Pathol, 88: 416-423.

9. Gonkowski S, Calka J (2012) Changes in pituitary adenylate cyclase-activating peptide 27-like immunoreactive nervous structures in the porcine descending colon during selected pathological processes. J Mol Neurosci, 48: 777-787.

10. Gonkowski S, Kaminska B, Bossowska A, Korzon M, Landowski P, Majewski M (2003) The influence of experimental Bacteroides fragilis infection on substance $P$ and somatostatin-immunoreactive neural elements in the porcine ascending colon: a preliminary report. Folia Morphol, 62: 455-457.

11. Gonkowski S, Burlinski P, Calka J (2009) Proliferative enteropathy $(\mathrm{PE})$-induced changes in galanin-like immunoreactivity in the enteric nervous system of the porcine distal colon. Acta Vet Beograd, 59: 321-330. 
12. Gonkowski S, Kaminska B, Landowski P, Skobowiat C, Burlinski P, Majewski M, Calka J (2009) A population of zinc transporter 3-like immunoreactive neurons is present in the ganglia of human descending colon. Adv Clin Eexp Med, 18: 243-248.

13. Gonkowski S, Burlinski P, Skobowiat C, Majewski M, Arciszewski MB, Radziszewski P, Calka J (2009) Distribution of cocaine- and amphetamine-regulated transcript-like immunoreactive (CART-LI) nerve structures in the porcine large intestine. Acta Vet Hung, 57: 509-520.

14. Gonkowski S, Kaminska B, Burlinski P, Kroll A, Calka J (2009) The influence of drug-resistant ulcerative colitis on the number of cocaine- and amphetamine-regulated transcript peptide-like immunoreactive (CART-LI) mucosal nerve fibres of the descending colon in children. Przegl Gastroenterol, 4: 147-151.

15. Gonkowski S, Burlinski P, Skobowiat C, Majewski M, Calka J (2010) Inflammation- and axotomy-induced changes in galanin-like immunoreactive (GAL-LI) nerve structures in the porcine descending colon. Acta Vet Hung, 58: 91-103.

16. Gonkowski S, Burlinski P, Szwajca P, Calka J (2012) Changes in cocaine- and amphetamine-regulated transcript-like immunoreactive (CART-LI) nerve structures of the porcine descending colon during proliferative enteropathy. Bull Vet Inst Pul, 56: 199-203.

17. Gunnarsdóttir A, Wierup N, Larsson LT, Kuhar MJ, Ekblad E (2007) CART-peptide immunoreactivity in enteric nerves in patients with Hirschsprung's disease. Eur J Pediatr Surg, 17: 184-189.

18. Henning RJ, Sawmiller DR (2001) Vasoactive intestinal peptide: cardiovascular effects. Card Res, 49: 27-37.

19. Kasparek MS, Fatima J, Iqbal CW, Duenes JA, Sarr MG (2007) Role of VIP and Substance P in NANC innervation in the longitudinal smooth muscle of the rat jejunuminfluence of extrinsic denervation. J Surg Res, 141: 22-30.

20. Kristensen P, Judg ME, Thim L, Ribel U, Christjansen KN, Wulff BS, Clausen JT, Jensen PB, Madsen OD, Vrang N, Larsen PJ, Hastrup S (1998) Hypothalamic CART is a new anorectic peptide regulated by leptin. Nature, 393: 72-76.

21. Majewski M, Bossowska A, Gonkowski S, Wojtkiewicz J, Brouns I, Scheuermann DW, Adriaensen D, Timmermans JP
(2002) Neither axotomy nor target-tissue inflammation changes the NOS- or VIP-synthesis rate in distal bowel-projecting neurons of the porcine inferior mesenteric ganglion (IMG). Folia Histochem Cytobiol, 40: 151-152.

22. Okumura T, Yamada H, Motomura W, Kohgo Y (2000) Cocaine- amphetamine-regulated transcript (CART) acts in the central nervous system to inhibit gastric acid secretion via brain corticotrophin-releasing factor system. Endocrinology, 141: 2854-2860.

23. Skobowiat C, Gonkowski S, Calka J (2010) Phenotyping of sympathetic chain ganglia (SChG) neurons in porcine colitis. J Vet Med Sci, 72: 1269-1274.

24. Spiess J, Villarreal J, Wale W (1981) Isolation and sequence analysis of a somatostatin-like polypeptide from ovine hypothalamus. Biochemistry, 20: 1982-1988.

25. Tebbe JJ, Ortmann E, Schumacher K, Mönnikes H, Kobelt $P$, Arnold R, Schäfer MK (2004) Cocaine- and amphetamine-regulated transcript stimulates colonic motility via central CRF receptor activation and peripheral cholinergic pathways in fed conscious rats. Neurogastroenterol Motil, 16: 489-496.

26. Wierup N, Gunnarsdóttir A, Ekblad E, Sundler F (2007) Characterisation of CART-containing neurons and cells in the porcine pancreas, gastro-intestinal tract, adrenal and thyroid glands. BMC Neurosci, 8: 1471-2202.

27. Wojtkiewicz J, Gonkowski S, Bladowski M, Majewski M (2012) Characterization of cocaine and amphetamineregulated transcript-like immunoreactive (CART-LI) enteric neurons in the porcine small intestine. Acta Vet Hung, 60: $371-881$.

28. Wojtkiewicz J, Gonkowski S, Rowniak M, Crayton R, Majewski M, Jalynski M (2012) Neurochemical characterization of zinc transporter 3-like immunoreactive $(\mathrm{ZnT3}(+))$ neurons in the intramural ganglia of the porcine duodenum. J Mol Neurosci, 48:766-776.

29. Wojtkiewicz J, Rowniak M, Gonkowski S, Crayton R, Majewski M, Robak A, Bialkowska J, Barczewska M (2012) Proliferative enteropathy (PE)-induced changes in the calbindin-immunoreactive (CB-IR) neurons of inferior mesenteric ganglion supplying the descending colon in the pig. J Mol Neurosci, 48: 757-765. 